\title{
First Report of Pycnidial Stage of Didymella bryoniae, the Causal Fungus of Gummy Stem Blight on Cantaloupe (Cucumis melo var cantalupensis) in Egypt
}

\section{A.A. El-Wakil and Amal A. Khalil}

Seed Pathol. Res. Dept., Plant Pathol. Res. Inst., ARC.

Cummy stem blight incited by Didymella bryoniae Auersw Ianamorph of Mycosphaerella Rehm is one of the most important diseases of cucurbits causing considerable damage in many countries.

Although disease symptoms are well known but the causal pathogen has never been isolated and/or identified in Egypt, moreover, stem injuries may provoke a similar host response.

In Egypt, the disease was observed in all cucurbits fields causing considerable damage especially on plants with sprinkling irrigation system. Diseased cantaloupe samples collected from El-Bostan (Beheira Governorate) showed red to brown stem cankers that produced gummy exudates and the diseased fruits showed spots of greasy green color which turn brown (Fig. 1).

The pathogen was isolated from the inner part of the stem and cultured on potato dextrose agar (PDA) in Petri dishes kept in the dark at $25^{\circ} \mathrm{C}$ for 7 days. The fungal growth was examined using stereomicroscope and compound microscope. For culture purification, hyphal tips were cultured on water agar then transferred aseptically onto V-8 juice agar and incubated at $25^{\circ} \mathrm{C}$ in the dark.

Aerial mycelium of the fungus was appeared at the center of rough surface and undulated colony. After 15 days, pycnidia were observed embedded in the mycelial growth as small black irregular bodies (Fig. 2a). The ooze of pycinidiospores is observed on mature pycinidia (Fig. 2b). Pycnidiospores are slightly smaller and non-septate $(6-13 \times 3-6 \mu \mathrm{m})$ (Fig. 2c). Pathogenicty test showed the same symptoms of the disease on cantaloupe seedlings.

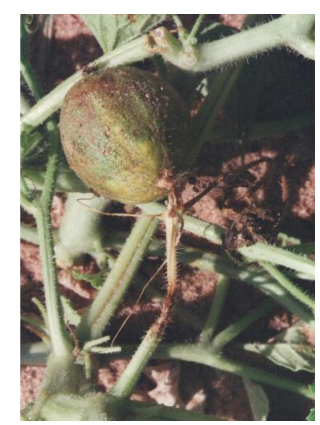

Fig. 1

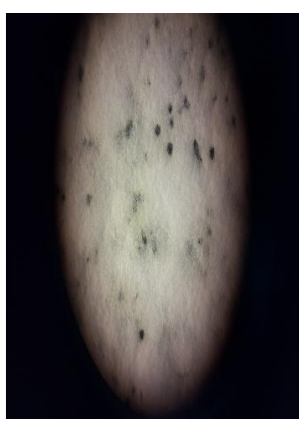

Fig. 2a (25X)

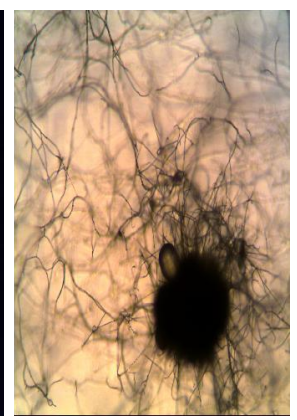

Fig. 2b (50 X)

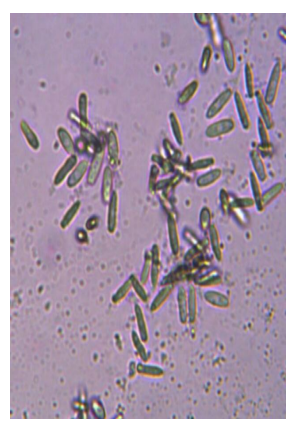

Fig. 2c (100X) 


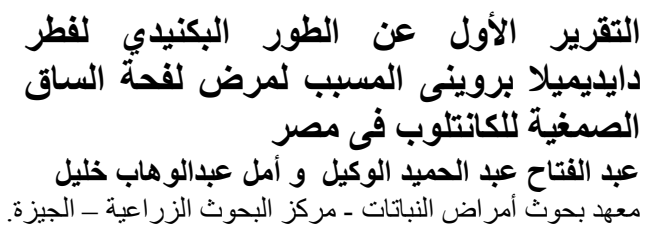

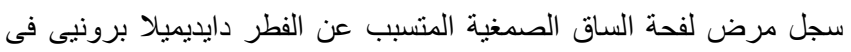

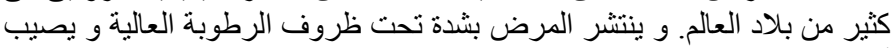

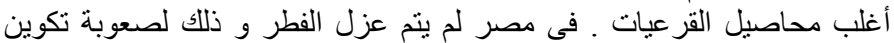

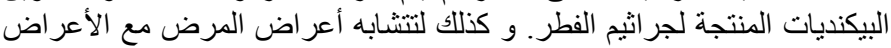

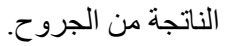

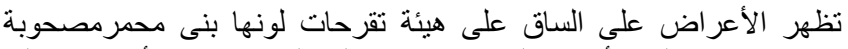

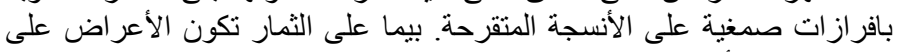

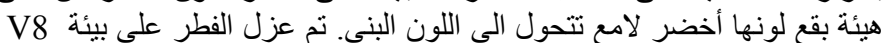

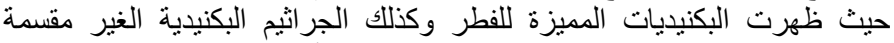

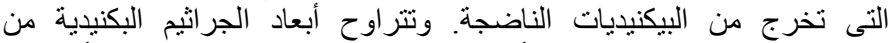

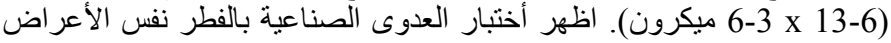

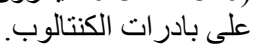

